\title{
Enzymatic-Gravimetric Estimation of the Content and Composition of Insoluble Dietary Fiber in Selected Cereals, Pulses, and Starchy Roots and Tubers
}

\author{
Abu Torab M. A. Rahim ; Sanjida Akter, and Nusrat Ahmed \\ Institute of Nutrition and Food Science, University of Dhaka, Dhaka-1000, Bangladesh
}

\begin{abstract}
An enzymatic-gravimetric method was employed to determine the content of insoluble dietary fiber and lignin in 4 cereals, 5 pulses, 4 starchy roots, and 3 tubers along with some of their varieties. The cultivars were identified at Bangladesh Agriculture Research Council and noted as their high yielding varieties released within last decade for cultivation in Bangladesh. Insoluble dietary fiber content, equivalent to alpha-amylase treated neutral detergent fiber (termed as E-NDF), was in a range from $0.97 \mathrm{~g}$ to $10.45 \mathrm{~g}$ for cereals, $8.18 \mathrm{~g}$ to $25.66 \mathrm{~g}$ for pulses, $2.62 \mathrm{~g}$ to $6.88 \mathrm{~g}$ for roots, and $2.26 \mathrm{~g}$ to $8.11 \mathrm{~g}$ for tubers per $100 \mathrm{~g}$ raw sample. Cell wall polysaccharides and Lignin were estimated from the E-NDF fraction sequentially using the methods of Van Soest and co-workers. Hemicellulose was found dominant among cell-wall polysaccharides in all the studied materials (up to $24.85 \%$ in pulses). Cell wall polysaccharide and lignin were not detected in some of the studied samples. Highest amount of cellulose was found in 'Gourab' variety of wheat $(3.48 \%)$ while highest amount of lignin was estimated in sweet potato $(2.87 \%)$. The results will, thus, provide a source data for dietary calculations.
\end{abstract}

Key Words: Insoluble dietary fiber, Hemi-cellulose, Lignin, Enzymatic-gravimetric method

\section{Introduction}

Dietary fiber should be considered as part of the carbohydrates in foods ${ }^{1}$. However, given the amorphous nature of fiber in foods and the methodologies available for its quantification, definition of dietary fiber (DF) is method specific. DF can be best viewed as a biological entity rather than a chemically defined component of the diet ${ }^{2}$.

The major problem in the choice of method lies in the definition of DF and its interpretation in an analytical context. The selection of appropriate method for use should be based on the intended use and whether the method was developed considering that use ${ }^{1}$. Currently, dietary fiber analysis methodologies are classified into three major categories: nonenzymatic-gravimetric, enzymatic-gravimetric, and enzymatic-chemical methods. There are now five methods that have been approved by AOAC for the analysis of total DF fiber in foods ${ }^{3}$. Many studies showed relatively linear correlations between methods, but these are usually food type dependent. The AOAC method 992.16

Bangladesh Journal of Nutrition. Vol 18-19, December 2005-2006. Institute of Nutrition and Food Science, University of Dhaka-1000, Bangladesh.

* Author for Correspondence 
is an enzymatic-gravimetric method known as the "Mongeau" method that determines total fiber by summing the results of a soluble fiber analysis with an insoluble (neutral detergent fiber, NDF) analysis. Mongeau and Brassard ${ }^{4}$ incorporated amylase pancreatic in the NDF method to permit a correct digestion of starch. The NDF method though measures one portion (the insoluble dietary fiber, IDF) of total DF, yet there are welldefined relationships between NDF intake and physiological actions such as digestibility, mineral availability and other nutrient interactions $s^{5}$. Cell-wall polysaccharides can be estimated from NDF residues by the methods of van Soest ${ }^{6,7}$.

This article presents the content and composition of IDF in some selected cereals, pulses, starchy roots, and tubers of Bangladesh.

\section{Materials and methods}

\section{Sample Collection and Preparation}

Food samples were purchased from local market of Dhaka city as well as from farmer's field of nearby districts. Collected samples were fresh, well shaped and free from insect bite and other deformities. They were selected at random from the stock lot of the seller. Food samples were collected during their pick seasons. Collected samples were identified at the Bangladesh National Herbarium, Dhaka. On the other hand, variety and/or cultivars types were identified at the Bangladesh Agriculture Research Institute (BARI).

After collection, vegetable samples were cleanly washed with tap water and air dried. Portion of all samples were separated immediately for moisture estimation at $105^{\mathrm{O}}$ $\mathrm{C}$ for 6 hours in an open air oven ${ }^{8}$. Rest of the food samples were then taken on stainless steel tray, dried at $80^{\circ} \mathrm{C}$ in an oven for overnight (16-18 hrs). This drying method was validated in our earlier study ${ }^{9}$. The dried samples thus prepared were then grinded in a domestic grinder and passed through a 40-mm sieve. The powdered sample was taken into an air-dried plastic container, caped under nitrogen flow and put into desiccators at room temperature until analysis.

\section{Fiber analysis}

IDF was estimated after the method of Mongeau and Brassard ${ }^{4}$ that incorporated amylase pancreatic in the NDF method of van Soest and Wine ${ }^{6}$ to permit a correct digestion of starch. Since alpha-amylase was used to NDF estimation, the IDF obtained was termed as Enzymatic-NDF (E-NDF). The enzymatic modification was as follows: $50 \mathrm{~mL}$ phosphate buffer ( $\mathrm{pH}$ 6.0) within $0.1 \mathrm{~mL}$ heat-stable alpha-amylase (Termamyl, Sigma) was added to $1 \mathrm{~g}$ of sample and allowed for digestion of starch at $100^{\circ} \mathrm{C}$ for 30 min. The extractives were filtered through a sintered glass crucible under water jet suction. The crucibles were filled again with neutral detergent solution for the extraction of E-NDF. Acid detergent fiber (ADF), and acid insoluble lignin (Klason lignin) were determined sequentially from the E-NDF fraction according to Van Soest methods $s^{6,7}$ with suitable adjustments ${ }^{9}$. The amount of Cellulose and Hemi cellulose were calculated by subtracting Lignin from ADF (ADF - Lignin) and ADF from ENDF (E-NDF - ADF) respectively. The whole fiber analysis procedure is summarized in a flow chart (Figure 1). 
Figure 1 Flow Chart for Enzyme Treatment and Sequential Estimation of IDF and Lignin

Sample

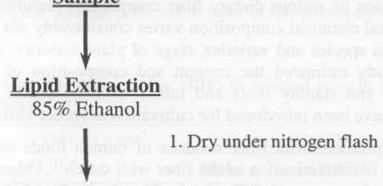

Enzyme Treatment in Phosphate Buffer

$0.1 \mathrm{ml} \alpha$-amylase in $50 \mathrm{ml}$ phosphate buffer ( $\mathrm{pH} 6.0-6.2)+1 \mathrm{~g}$ dry sample

1. Heat at $100^{\circ} \mathrm{C}$ with gentle shaking;

2. 30 min incubation

\section{Readjustment of Medium $\mathbf{p H}$}

$0.1 \mathrm{~N} \mathrm{NaOH}, \mathrm{pH} 6.9-7.0$

\section{Sample for NDF Estimation}

1. $50 \mathrm{ml}$ Neutral Detergent Solution: $18.61 \mathrm{~g}$

EDTA + 30g Sodium Lauryl Sulphate +

$6.81 \mathrm{~g}$ Sodium Borate Dechadydrate + $4.65 \mathrm{~g} \mathrm{Na}_{2} \mathrm{HPO}_{4}+$ up to $1000 \mathrm{ml} \mathrm{H}_{2} \mathrm{O}$

2. Reflux at boiling temperature for $1 \mathrm{~h}$

3. Pass through sintered glass crucible; dry

\section{E-NDF Residue}

1. $50 \mathrm{ml}$ Acid Detergent Solution:

$20 \mathrm{~g}$ Cityl Trimethyl Ammonium

Borate in $1 \mathrm{~L}$ of $1 \mathrm{~N} \mathrm{H}_{2} \mathrm{SO}_{4}$

2. Reflux at boiling temperature for $1 \mathrm{~h}$

\section{$\underline{\text { ADF Residue }}$}

1. Digestion with excess volume of $72 \%$ $\mathrm{H}_{2} \mathrm{SO}_{4}$ (w/w) for $3 \mathrm{hrs}$.

2. Wash excessively with water; Dry

\section{Lignin Residue}




\section{Results and Discussion}

The proportion of various dietary fiber components (soluble and insoluble) as well as their individual chemical composition varies considerably not only from food to food but also on plant species and varieties, stage of plant maturity, and parts of the plant ${ }^{10}$. The present study estimated the content and composition of IDF in some selected cereals, pulses, and starchy roots and tubers of Bangladesh. These varieties of the selected foods have been introduced for cultivation in recent years by BARI.

The major problem with fiber residues of human foods obtained by Van Soest's NDF procedure is contamination of the fiber with starch ${ }^{11}$. Other problems include lipid and protein interference, and difficulty in filtration ${ }^{12}$. Starch in low concentrations is solubilized in the neutral detergent solution (NDS), but certain types e.g., modified and retrograded starch and its high concentrations can lead to filtration problems as well as overestimations of $\mathrm{DF}^{12}$. To gelatinize and hydrolyze starch, different methods employ either only $\alpha$-amylases or only glucoamylase or a combination of both types of amylases (reviewed by Marlett et. al. ${ }^{13}$ ). Mongeau and Brassard ${ }^{4}$ incorporated amylase pancreatic in the NDF method (AOAC method \# 992.16) to permit a correct digestion of starch and thus, adopted in the current study. As a result even in starchy materials, such as wheat flour and potatoes, only a small amount of starch remained in the IDF residue that is available to glucoamylase treatment. The remained starch in IDF fraction, often termed as "Resistant Starch", is mainly retrograded amylose and recently has been suggested to be included under DF components ${ }^{2}$. This was the reason why glucoamylase treatment was omitted in the adopted NDF procedure.

Among the studied cereals the highest amount of IDF (equivalent to E-NDF) was found in the reddish Gourab variety $(16.17 \%)$ of wheat. Whole-wheat flour (white) has been reported $^{14}$ to contain $13.12 \%$ of TDF and $10.91 \%$ of IDF while whole wheat and grain was reported ${ }^{15}$ to contain fiber from $16.69 \%$ to $18.42 \%$. Mori ${ }^{18}$ has also reported that two varieties of Japanese polished rice Koshiji-sosei and Kiyonishiki contained $1.91 \%$ and $1.44 \%$ of TDF respectively. In this respect the two parboiled rice, NazirShyle and Bashful, contained a little higher amounts of E-NDF (1.91\% and $2.11 \%$ respectively) while non-parboiled rice Kalozira contained similar amount $(0.97 \%)$ compared to those two Japanese varieties. Kaon, on the other hand, contained lowest amount of E-NDF $(8.61 \%)$ among the cereals studied. Among the five different kinds of pulses, Kheshari Dhal contained the highest amount of IDF $(25.66 \%)$ and pilled Cholar dhal (Bengal Gram) contained the lowest $(8.18 \%)$. These results are also comparable with other reported values ${ }^{14}$.

Cereals are reported to be rich in noncellulosic polysaccharides i.e., hemicellulose, pectins, gums, and mucilages ${ }^{14}$. Since ADF (Table 1) and lignin (Table 2) were not detected in rice, the E-NDF values (total amount of cellulose, hemicellulose and lignin) may be taken as mainly composed of hemicellulose (Table 2). The hemicellulose values of the studied cereals ranged from $0.97 \%$ to $11.99 \%$. These results were found comparable with reported values ${ }^{10,14,15}$. Among all studied cereals the highest amount of cellulose was found in the wheat variety Gourab $(3.48 \%)$. On the other hand, amounts of cellulose in the pulses were found to be lower $(0.37 \%-1.3 \%)$ than cereals (Table 2). 
And as expected, hemicelluloses like in cereals were found to be higher in the pulses $(7.03 \%-24.85 \%)$. Lignin was not detected in most of the pulses except in Khesari dhal $(0.45 \%)$.

Table 1 Content of insoluble dietary fiber (IDF) in selected cereals, pulses, and starchy roots and tubers ${ }^{1}$

\begin{tabular}{clccc}
\hline \multirow{2}{*}{$\begin{array}{c}\text { Foods } \\
\text { Cultivar name }\end{array}$} & \multicolumn{3}{c}{ Amount $(\mathrm{g} / 100 \mathrm{~g}$ raw sample) } \\
\cline { 3 - 5 } 1. Cereals & & Water & E-NDF & ADF \\
Rice & Nazir Shyle & $13.34 \pm 0.8$ & $1.91 \pm 0.13$ & $\mathrm{Tr}^{3}$ \\
& Bashful & $13.44 \pm 0.7$ & $2.11 \pm 0.24$ & $\mathrm{Tr}$ \\
& Kalozira & $13.79 \pm 0.8$ & $0.97 \pm 0.35$ & $\mathrm{Tr}$ \\
Wheat & Gourab & $12.05 \pm 0.9$ & $16.17 \pm 0.09$ & $4.18 \pm 1.13$ \\
& Kanchan & $11.81 \pm 0.8$ & $10.45 \pm 0.86$ & $2.04 \pm 0.26$ \\
Maize & Mohor & $14.90 \pm 0.4$ & $8.61 \pm 0.52$ & $1.74 \pm 0.25$ \\
Kaon & Teetas & $10.03 \pm 0.8$ & $4.85 \pm 0.31$ & $0.66 \pm 0.01$
\end{tabular}

2. Pulses

Khesari

Black Gram

Green Gram

Lentil

Bengal Gram

3. Starchy Roots

\section{Arum}

Kohlrabi

Shak Alu

Turnip

4. Starchy Tubers

Potato
Ol kachu

Ol kapi

Shak Alu

Shalgam

$$
10.91 \pm 0.4
$$$$
9.58 \pm 0.5
$$

$10.10 \pm 0.2$

$12.40 \pm 0.6$

$9.95 \pm 0.8$

$78.72 \pm 1.8$

$87.50 \pm 1.3$

$78.89 \pm 1.7$

$90.96 \pm 2.1$
$25.66 \pm 0.61$

$21.42 \pm 2.39$

$19.44 \pm 3.57$

$13.86 \pm 1.12$

$8.18 \pm 0.40$

$2.62 \pm 0.01$

$6.88 \pm 0.17$

$4.94 \pm 0.05$

$4.88 \pm 0.01$
$\mathrm{Tr}^{3}$

$\mathrm{Tr}$

$\mathrm{Tr}$

$$
13
$$


Among the studied roots and tubers the IDF (E-NDF) values ranged from $2.26 \%$ to $8.11 \%$ as per raw weight. The highest amount was found in Olkapi $(6.88 \%)$ among the root vegetables and in Sweet Potato $(8.11 \%$ ) among tuber vegetables. Cellulose was reported to be high in vegetables and some fruits, while the proportion of lignins is highest in fruits ${ }^{10}$. While the cellulose values among all studied roots and tubers were in a range of $0.23 \%-1.28 \%$, the hemicellulose values were in range of $1.55 \%-3.96 \%$. A comparison of noncellulosic polysaccharides, and Klason lignin in food was conducted by Southgate which indicated that lignin contents of raw vegetables usually ranged from $<1 \%$ to $13 \% \%^{19}$. The lignin values of the tubers and roots were found to be in a range of $0.32 \%-2.87 \%$ (Table 2 ).

Table 2 Content of cell-wall polysaccharides and lignin in selected cereals, pulses, and starchy roots and tubers ${ }^{1}$

\begin{tabular}{|c|c|c|c|c|}
\hline \multirow[t]{2}{*}{ Foods } & \multirow[t]{2}{*}{ Cultivar name ${ }^{2}$} & \multicolumn{3}{|c|}{ Amount (g/100 g raw sample) } \\
\hline & & Cellulose & Hemicellulose & Lignin \\
\hline 1. Cereals & Nazir Shyle & $\mathrm{Tr}$ & $1.91 \pm 0.13$ & $\mathrm{ND}^{3}$ \\
\hline \multirow[t]{2}{*}{ Rice } & Bashful & $\operatorname{Tr}$ & $2.11 \pm 0.24$ & ND \\
\hline & Kalozira & $\operatorname{Tr}$ & $0.97 \pm 0.35$ & ND \\
\hline \multirow[t]{2}{*}{ Wheat } & Gourab & $3.48 \pm 0.88$ & $11.99 \pm 1.04$ & $0.70 \pm 0.26$ \\
\hline & Kanchan & $1.63 \pm 0.24$ & $8.41 \pm 0.59$ & $0.41 \pm 0.01$ \\
\hline Maize & Mohor & $1.74 \pm 0.25$ & $6.87 \pm 0.28$ & ND \\
\hline Kaon & Teetas & $0.66 \pm 0.01$ & $4.19 \pm 0.31$ & ND \\
\hline \multicolumn{5}{|l|}{ 2. Pulses } \\
\hline Khesari & & $0.37 \pm 0.01$ & $24.85 \pm 0.60$ & $0.45 \pm 0.02$ \\
\hline Black Gram & & $1.30 \pm 0.23$ & $20.12 \pm 2.03$ & $\mathrm{ND}^{2}$ \\
\hline Green Gram & & $0.88 \pm 0.07$ & $18.56 \pm 1.05$ & ND \\
\hline Lentil & & $0.76 \pm 0.01$ & $13.10 \pm 1.12$ & ND \\
\hline Bengal Gram & & $1.15 \pm 0.10$ & $7.03 \pm 0.44$ & ND \\
\hline \multicolumn{5}{|l|}{ 3. Starchy Roots } \\
\hline Arum & Ol kachu & $0.64 \pm 0.02$ & $1.55 \pm 0.15$ & $0.43 \pm 0.13$ \\
\hline Kohlrabi & Ol kapi & $2.74 \pm 0.14$ & $2.84 \pm 0.14$ & $1.30 \pm 0.17$ \\
\hline Shak Alu & Shak Alu & $1.90 \pm 0.26$ & $2.01 \pm 0.04$ & $1.03 \pm 0.35$ \\
\hline Turnip & Shalgam & $1.89 \pm 0.07$ & $2.07 \pm 0.06$ & $0.92 \pm 0.14$ \\
\hline \multicolumn{5}{|l|}{ 4. Starchy Tubers } \\
\hline \multirow[t]{2}{*}{ Potato } & Holland, white & $0.60 \pm 0.01$ & $1.46 \pm 0.11$ & $0.32 \pm 0.01$ \\
\hline & Holland, pink & $0.75 \pm 0.05$ & $1.74 \pm 0.37$ & $0.32 \pm 0.05$ \\
\hline Jam Alu? & Jam Alu & $0.23 \pm 0.07$ & $1.62 \pm 0.08$ & $0.42 \pm 0.01$ \\
\hline Sweet Potato & MistiAlu & $1.28 \pm 0.02$ & $3.96 \pm 0.02$ & $2.87 \pm 0.18$ \\
\hline
\end{tabular}

\footnotetext{
${ }^{1}$ Results are expressed as mean \pm s.d. of triplicate estimation of each sample.

${ }^{2}$ Local Variety / Cultivar names were identified at BARI.

${ }^{3}$ Trace amount $\left(<0.005 \mathrm{~g} / 100 \mathrm{~g}\right.$ raw sample); ${ }^{4}$ Not Detected
} 
Fruits, vegetables and cereal products are usually valued for their nutrient content but they are now also regarded as rich sources of dietary fiber. A general survey of DF prepared from different vegetable and crop sources have been conducted in the West and revealed that the chemical and physical properties of vegetable fiber can be characteristics of the sources ${ }^{10}$. No such comprehensive analysis has been made previously in our country. The findings of the present study will provide baseline data for the content and composition of food fiber in some selected foodstuffs. These data may be useful for the calculation of the consumption of dietary fiber.

\section{References}

1 Greenfield H. and DAT Southgate. Food Composition Data: Production, Management and Use. FAO, Rome, 2003.

2 FAO. Carbohydrates in Human Nutrition. Report of a joint FAO/WHO expert consultation, Rome, 1997. FAO Food and Nutrition Paper 66, Rome, 1998.

3 AOAC International. Total, Soluble and Insoluble Dietary Fiber in Foods. In: Official Methods of Analysis, $16^{\text {th }}$ Ed. 1995

4 Mongeau R, Bassard R. Determination of neutral detergent fiber in breakfast cereals: pentose, hemicellulose and lignin content. J Food Sci 1982; 47:550-55.

5 Baer DJ, Rumpler WV, Miles CW, and Fahey GC. Dietary Fiber Decreases the Metabolizable Energy Content and Nutrient Digestibility of Mixed Diets Fed to Humans. J Nutrition 1997; 127(4):579-86.

6 Van Soest PJ. Use of detergent in the analysis of fibrous feeds. II. A rapid method for the determination of fiber and lignin. J Assoc off Anal Chem 1963; 46:829-35.

7 Van Soest PJ and Wine RH. Use of detergent in an analysis of fibrous feeds. IV. Determination of plant cell constituents. J Assoc Anal Chem 1967; 50:50-55.

8 NIN. A Manual of Laboratory Techniques, Indian Council of Medical Research (ICOMR), National Institute of Nutrition, Hyderabad, 2003.

9 Huq F, Fatema K and Rahim ATMA. Content and composition of dietary fiber in some Bangladeshi vegetables. Diab Endocr J 2001; 29(2):61-66.

10 Lanza E. and Butram R. In a critical review of food fiber analysis and data; J Am Diet Assoc 1986; 86(6):732-43.

11 Marlett JA and Lee SC. Dietary fiber- Lignocellulose and Hemi cellulose contents of selected foods determine by modified Van Soest procedures. J Food Sci 1980; 45:1688-93.

12 Spiller GA. Dietary Fiber in Human Nutrition, $2^{\text {nd }}$ edn., CRC Press Inc., London, 1993, p. 15-18.

13 Marlett JA. Analysis of Dietary Fiber in Human Foods In: Dietary Fiber Chemistry, Physiology, and Health Effects, eds. Kritchevsky D and Anderson B, Plenum Press, New York, 1989, p. 43.

14 Rorertson JB. Dry matter, Ash, Crude Protein, Total dietary fiber, Soluble fiber, Neutral detergent residue, Hemicellulose, Cellulose and Lignin content of selected foods. In: Dietary Fiber in Human Nutrition, $2^{\text {nd }}$ edn., Spiller GA ed., CRC Press Inc., London, 1993, pp. 49-52.

15 Mori B. Contents of dietary fiber in some Japanese foods and the amount ingested through Japanese meals. Nutr Report Intn 1982; 26 (2):159-66 